\title{
Doing Care with Integrity and Emotional Sensibility-Reciprocal Encounters in Psychiatric Community Care of Older People with Mental Health Problems
}

\author{
Lis Bodil Karlsson ${ }^{1,2}$, Elisabeth Rydwik ${ }^{2,3}$ \\ ${ }^{1}$ Department of Social and Psychological Studies, Karlstad University, Karlstad, Sweden \\ ${ }^{2}$ Research and Development Unit, Jakobsberg's Hospital, Stockholm County Council, Järfälla, Sweden \\ ${ }^{3}$ Deptartement of Neurobiology, Care Sciences and Society, Division for Physiotherapy, Karolinska Institute, \\ Huddinge, Sweden \\ Email: lis-bodil.karlsson@kau.se, lis.karlsson@sll.se, elisabeth.rydwik@sll.se
}

Received November $11^{\text {th }}, 2012$; revised December $28^{\text {th }}$, 2012; accepted January $11^{\text {th }}, 2013$

\begin{abstract}
Copyright (c) 2013 Lis Bodil Karlsson, Elisabeth Rydwik. This is an open access article distributed under the Creative Commons Attribution License, which permits unrestricted use, distribution, and reproduction in any medium, provided the original work is properly cited.
\end{abstract}

\begin{abstract}
The article focuses on the experiences of community care workers in the encounter with older persons suffering from mental health problems, such as mental illness and disability. The purpose is to describe and discuss opportunities for and challenges to reciprocal encounters with these older people in community care, based on statements from professionals interviewed. Structured conversations with five focus groups were organised, consisting of 26 participants, including nurses' assistants, assistant nurses, nurses, social workers and occupational therapists. The participants in the focus groups highlight the essence of being involved and create space for a reflective attitude. Clinical implications will be presented as well.
\end{abstract}

Keywords: Focus Group; Social Care; Mental Illness; Psychiatric Disability

\section{Introduction}

Since the major Swedish mental hospitals were closed and the Psychiatric Care Reform of 1995 was implemented (Prop. 1993/94:218), new forms of municipal and social care have developed in Sweden, such as supported housing, day care centres and case managers (Berggren \& Gunnarsson, 2010). One consequence of the reform is that psychiatric clinics only treat patients during an acute mental illness, while the social services within the community are responsible for those discharged from the clinics (Karlsson, 2009; Markström, Sandlund, \& Lindqvist, 2004). A similar change has occurred in other Western countries. This de-institutionalisation has inspired research on people with psychiatric disabilities as care clients in the community, and has led to greater knowledge from a client perspective regarding their opportunities to recover from severe mental disorders (Barker \& BuchananBarker, 2011; Davidson et al., 2005; Deegan, 2003; Tierney \& Kane, 2011). The specific knowledge of professional social and psychiatric care providers are a key aspect of this shift, as are their methods of working in the community. Other aspects are general attitudes towards mental health and the negative consequences of stigma (Link \& Phelan, 2001). The shift is occurring in a different arena than the closed world of psychiatryspecifically in the community and in people's homes (Topor, 2005). Without denying the individuals' mental suffering and need for help, this should reasonably result in opportunities for a more reciprocal encounter than previously (Topor, 2005: p. 29). This in turn affects the clients' opportunities to act, as the staff personnel are now on their turf, in their homes:
These changed encounters result in new knowledge. New, reciprocal knowledge. Most of the problems remain. The old roles do not vanish simply by changing venue. At the same time, the professional and the client begin to get to know each other in a new way. The focus is no longer on the client's shortcomings, flaws and symptoms, but instead on his abilities, knowledge and his creative ways of dealing with his problems. This knowledge is more complex, more nuanced. The problems are placed in the context of their daily lives, giving them new meaning (Topor, 2005: p. 29, our translation).

In this context, it is therefore essential to also focus on the professionals' experience. Expectations of reciprocity in the encounter are not uncomplicated, and in this article we describe and discuss the attitudes of professionals in care based on their perspective nearly two decades after psychiatric care was shifted to the community in Sweden.

When social-work researcher Andersson (2009a, 2009b) describes for example how residential support works for people with mental health problems such as mental illness and disabilities, she distinguishes between doing everyday tasks and talking with clients (everyday conversation), which occurs in an ongoing interaction-remembering that the "inter" implies mutuality (2009b). Andersson emphasises that this mutuality in the encounter between professional care provider and care user does not mean an exchange of transactions, material or immaterial. Rather, it implies a mutuality that occurs "during the time space in which the social interaction takes place” (2009a).

The sociologist Barron has coined the expression "a traditionally internalised care perspective” (Barron, 2009: p. 79) in 
which staff members solely perceive people with mental disabilities as care recipients - as objects. The opposite is critical thinking, which is to say reflecting on what clients are communicating through their behaviour rather than simply dismissing them as "difficult". This thinking must be combined with critical action, explains Barron-in other words an awareness of one's position of power in the encounter, or as she writes, “power-conscious care” (Barron, 2009: p. 66).

\section{The Secure Encounters Project}

To conduct new research on mental illness and disabilities available to workers in the community welfare care and service system, the Swedish government has invested a large amount of money in education and development projects

(http://www.socialstyrelsen.se/english [National Board of Health and Welfare]). Between 2009 and 2012 eight municipalities served by the Stockholm County Council, together with a regional Research and Development unit and a psychiatric clinic, initiated the training project Secure Encounter with money from this special initiative. The project trained front-line staff personnel who encounter older people suffering from mental health problems, such as mental illness and disabilities, in their daily work in various community-run welfare care and social services, such as day care centres, home care/help, care homes etc. In total, 320 community care workers were trained. For more information on the project we refer to the evaluation (Rydwik, Karlsson, Strandberg, Mattson, work in progress [in Swedish]). In another context we discuss the learning process of the professionals after completing training (Karlsson \& Rydwik, 2013).

\section{Aim and Research Question}

Since the de-institutionalisation in Sweden, a recurring topic of discussion has been the importance of the professional's approach, from the perspective of the client or user (Berggren \& Gunnarsson, 2010). Thus, it is vital in this context to understand the staff's experiences of opportunities for and challenges to reciprocity in care. Our article focuses on the experiences of community care workers in the encounter with older persons suffering from mental health problems, such as mental illness and disability. The purpose is to describe and discuss opportunities for and challenges to reciprocal encounters with these older people in community care, based on statements from the professionals. Reciprocity can be defined as "the equality of perceived investments in and outcomes from a relationship relative to the persons' own internal standards" (Prichard, 1969: p. 180, referenced in Thomas \& Rose, 2010). In fact, reciprocity is not only a necessity from the users' perspective, but also a prerequisite for care workers to feel satisfaction with their daily work (Thomas \& Rose, 2010; Rönning, 2002).

\section{Care, Recovery, and Mutual Relationships}

Rönning (2002) explains that definitions of the term care vary, in general along a scale in which one extreme is being vulnerable to those in power and dependent on the paternalistic whims of others. This is particularly interesting considering that the caring sciences are female dominated. The other extreme is that care can be viewed as an expression of genuine humanity. Rönning also feels that he sees three recurring aspects in the definitions of care: The first emphasises that care is based on emotions: "If there is no dedication to the other as a unique human being, there is less reason to be concerned about his or her well-being” (Rönning, 2002: p. 36). The second aspect is an expectation of practical action. However, instrumental action without emotion, or conversely solely emotion without adequate action, cannot be viewed as true care. Rönning also links practical action to practical competence. The third aspect highlights care as a "relational concept" in which the staff must constantly maintain a balance between paternalism and indulgence. Yet all the while the relationship de facto involves reciprocity: "The caregiver is also a receiver, not only of money (as in formal relationships) but also of positive emotional feedback". The feedback from the frail person may be very important for the "giver" or "care worker" (Rönning, 2002: p. 36). This reasoning emphasises reciprocity as a critical prerequisite for care.

McCann and Baker (2001) studied how to develop interpersonal relationships with young community care consumers suffering from psychotic illnesses. Although their research deals with professionals' interaction with young people, their reasoning is significant to our study. In order to create a mutual relationship with the nurses, McCann and Baker's study developed different strategies related to the nurses' own attitudes in their daily work. The researchers point out the necessity of attempting to understand the patient, which requires time, empathy and being prepared to listen to the patient's wishes and experiences. The other aspect the researchers emphasise for a mutual relationship is being friendly, in which honesty from the nurses' side is vital. The researchers highlight "the process of tuning in", which means that the nurses must consider their own attitude in the encounter. Yet another aspect of the encounter is "the process of self-disclosing"-revealing oneself as a person, which disarms the encounter between professional and consumer. One dimension of a mutual relationship is simply being there for the person in need. Another is "maintaining confidentiality", which may mean that the nurse does not talk to the consumer's family about issues the consumer considers sensitive. McCann and Baker (2001) prefer the word alliance because the relationship is characterised by an imbalance of power, rather than the word partnership, although others do use this word in the context, for example Borg and Kristiansen (2004). The latter emphasise the importance of the relationship between the professional and the consumer: "Mutual relating is building a relationship based on trust and mutual respect. At the same time, nurses need to be cognizant of and acknowledge their strengths and limitations in mutual relating. /.../ The process of mutual relation, is, at least partly, influenced by the characteristic of consumers or nurses, or both” (Borg and Kristiansen, 2004: p. 535).

In recent years the concept of recovery has gained ground as a description of how we can view people who have suffered from mental health problems. Reasoning about recovery can de facto give an understanding of the care relationship, even for people over 65. Borg and Kristiansen (2004) write of the necessity to help people with mental illness based on their own terms and thinking in terms of recovery instead of "the usual pattern of trying to assess, adjust, and fit service-users into existing services" (Borg and Kristiansen, 2004: p. 501). In fact, the staff personnel need to get the consumer involved rather than just being the object of measures. At the same time, the professionals need to be open to differences between individuals and aware of the unpredictability of life. Recovery is not something 
that professionals do with or for the person. Rather, a "mutual relationship" requires an awareness that context and relationships are crucial, which Borg and Kristiansen view as an expression of “a true, collaborative partnership” (Borg and Kristiansen, 2004: p. 501).

Borg and Kristiansen emphasise that the essence of a reciprocal relationship is a focus on "the service user as a person and fellow human being, not as an ill individual affected by a chronic disease” (Borg and Kristiansen, 2004: p. 202). The researchers refer to philosopher Martin Buber's reasoning that both parties create the relationship during the encounter and therefore what happens between the individuals is crucial: "A reciprocal relationship between helper and service user will involve a view of the affected person as capable and resourceful” (Borg and Kristiansen, 2004: p. 503).

In order to interpret our data we will further briefly connect to some theoretical issues developed by Goffman (1959/1990), such as his interpretation of face to face communication. Goffman states that people generally avoid open conflicts and prefer to strive to achieve consensus and unanimity. People's sense of tact leads them to take protective measures to avoid making others and themselves looking bad or causing any embarrassment. Goffman uses the theatrical performance in order to understand the techniques for impression management; people or the actors enter $a$ scene, the place where dramatic action takes place. A team is when individuals collaborate in the preparation of a routine, that is, a predetermined pattern of behavior. Each team's mission is to preserve the stability of how to perceive the situation and if necessary to hide some information. Goffman speaks of conspiratorial activities partly carried out in secret. Region is a distinct place by perception and perception barriers, thus demarcated from view or sound isolation. Front region or front stage is where the behavior is influenced by standards, such as moral norms or rules of not disturbing. Back region or backstage is a behind the scene where the facts pressed arrive in days. Here people can relax and be themselves. Each team's goal is to maintain the definition of the situation. All team members must be loyal, disciplined and take caution. These are defense techniques of impression management. A team member may change her/his behavior in order to save the situation, even distort facts. For example, if the person is lying, and are caught doing this, s/he needs to dismiss this with a playful attitude. Dramaturgical discipline required of each member of the team is to maintain its appearance. Good dramaturgical discipline is about the ability to manage voice and gestures, without revealing any true feelings.

Based on the referenced research, we would like to propose that the prerequisite for reciprocity is to know how, why and when to act in the encounter with the consumer. It should be emphasised in this context that a lack of reciprocity in relation to colleagues, managers and organisation can lead to burnout (Thomas \& Rose, 2010)_ - a result of an imbalance between the professional's efforts and the professional benefit received.

\section{Research Approach}

Using focus groups is an established method of collecting data on the group level about perceptions of a specific phenomenon (Morgan, 1997). We organised five focus groups with 26 participants, of which 21 were women and 5 men. Partici- pants were front-line community staff personnel who encounter older people with mental health problems in their daily work, such as nurse's assistants, assistant nurses, nurses, social workers, and occupational therapists. The number of participants in the groups varied from two to seven. The discussions were 90 120 minutes long and were all recorded.

Since it was vital in our study to understand the staff's experiences of opportunities for and challenges to reciprocity in care it was obvious that focus groups should be our first option. Data collected in focus groups are usually multifaceted and rich, as the method invites the participants to engage in a discussion in which phenomena taken up in the talks are examined in detail and usually from a variety of perspectives. This is how our five focus groups were conducted; thus, we received not only assessment data as a basis for a future report (Rydwik et al., 2012) but also a rich collection of empirical data in which the participants talk about their attitudes towards and approach to the old persons suffering from mental health problems. Essential questions concerned how the education project had influenced their relations to the older clients, relatives of the older persons and other colleagues on a daily basis and created the possibility of reciprocity. Many, sometimes long, narratives emerged during the talks as the participants in the focus groups examined opportunities and obstacles in the care relationship. These talks were later transcribed verbatim.

We used a hermeneutic method of interpreting our transcriptions, based on the principle that the meaning of one part can only be understood if it is placed in the context of the whole (Alveson \& Sköldberg, 2000). That is to say, one person's statement can only be interpreted in relation to her entire story. The whole is made up of various parts and can only be explained from the parts. The hermeneutic method is circular, which means that the researcher alternates between the whole and the parts, leading to a deeper understanding of both. Our analysis of the collected data started with a read-through of each transcription in order to focus on passages about the professionals' encounters with the care users and their relatives. We began by thinking about what questions the participants actually answered. One could say that we as researchers were in a silent dialogue with the text. In practice, we read through the transcripts line by line to answer what question was behind every statement. The questions arose from a pre-understanding, but evolved during the process of working with them. Why did the participants speak, act and react as they did? Did the participants give intentional responses? Unintentional ones? Then we compared similar sections and interpreted how they resembled each other. Being in dialogue with the text thus means adopting an exploratory attitude while at the same time being both close to and detached from the collected data. Various partial interpretations relate to an overall interpretation pattern as well as to facts and questions we pose regarding the material, according to Alvesson and Sköldberg (2000). Partial interpretations can thus be a part of an overall pattern, although no interpretation is found to be definitive-all must always be viewed as preliminary.

We followed the generally accepted ethical principles in connection with the recording of these conversations, such as informed consent. Any kind of data that might reveal the participants' identities or personal circumstances were removed (Kvale \& Brinkman, 2009). The project was approved by the ethics committee at Karolinska Hospital in Solna, Sweden 
$(2009 / 1382-31)$

\section{Results}

When we present our results below, we will first focus on the prerequisites for the professionals' work, which is about awareness of the client's feelings and what happens in the relationship between professional and client. The results clearly indicate the necessity of professionals maintaining a moral distance and therefore understanding that they don't always need to state obvious truths, but should modify their statements out of consideration for the client. In the encounter with family members, professionals must also understand and respect that they in turn have emotions to be dealt with. Sometimes a professional must also stand as a buffer between the client and a family member demanding certain measures.

\section{Sensitivity to the Older Person's Needs}

Working with older people suffering from mental health problems is enormously challenging and is never the same, according to the participants in our focus groups. Or as one of them-an assistant nurse in community care-points out, "no one day is like another, especially when you're out in the field, visiting different areas, houses, people. Everything varies”. Working with older persons with mental health problems on a daily basis requires a unique kind of sensitivity, our participants stress. Every client expects the professional to make them feel special. Therefore it is necessary to be sensitive to the older person's needs in their daily work.

Returning to our initial promise of problematising the possibilities of creating a reciprocal encounter between the care user suffering from mental health problems and caregivers, we must emphasise that simply knowing about methods or special techniques does not create a reciprocal relationship. Nor do we think it is enough that the caregivers state their good intentions. Fine words may often cover up a lack of reciprocity, rather than eliminating it.

The participants in our focus group agree that their approach to the clients and their families is the essence of their daily work. One assistant nurse working at a residence for people with mental health problems describes her attitude as continuously showing respect in the encounter. She illustrates this with a short story of one of her residents, who sometimes wets the bed at night, and the staff who have developed an approach that eases the resident's feelings of shame:

He's ashamed. He's ashamed to tell us. So he conceals it. You need to take a different approach, so he doesn't feel ashamed. So if I knock on his door and say, "Say, I have a washing machine that's available. Do you have anything that needs washing? Just toss me whatever you've got and I'll take care of it."

This assistant nurse is undeniably aware of the client's vulnerability and how his shame leads him to want to hide his wet bedclothes and pyjamas. If this were allowed to continue the client would eventually lead to a life of squalor. But chastising him or holding forced inspections of his bed sheets would in no way promote reciprocity. Therefore, the assistant nurse focuses instead on eliminating his shame, rather than the need to wash his bedclothes. Contrary to what one might think on first reading of this story, the assistant nurse is not focused on intervention or on a course of action; rather, she is interested in ap- proaching the man at his current emotional level—and therefore, from the moment he opens the door to his room, she must start communicating. We propose that this attitude de facto reflects an awareness of the other's feelings and how they affect the opportunity, and in fact are a requirement, for a reciprocal relationship. At the same time, her closing sentence says something special: “Just toss me whatever you've got and I'll take care of it”. Is her statement patronising? An expression of superiority? In our view, she catches the client off-guard, but her primary focus is on eliminating the feeling of shame, then she acts to take the bedclothes. Ergo, she avoids amplifying the man's shame. She takes protective measures to keep the man from looking bad. She has and demonstrates a sense of tact (Goffman, 1959/1990).

\section{Understanding Process Thinking and the Importance of Trust}

A female group leader in home help services talks about the complexity of their everyday work. The community support unit cannot simply ask the home help services to carry out a task, or send an order from: "This is human beings we're dealing with. People about whom we need to have as much information as possible so that we can get through to them as soon as possible". Throughout the focus group interviews, showing tact in the encounter with the older persons comes up as an essential element (Goffman, 1959/1990). In order to even be able to initiate practical action, the professional must reach out to the clients and earn their trust, which in turn requires a genuine meeting. Respect has to be there before practical caregiving is even possible, or as an assistant nurse in home help services says:

Some of them [the elderly] need help around the house, but they don't want it. They absolutely do not want it. So I mean, you have to win them over somehow. You have an assignment, to go there and tidy up, you've got maybe fifteen minutes to do it in, and the cleaning is important so she doesn't live in squalor. The food is very important, otherwise she won't eat.

But everyone knows that you can't start out with the food and the tidying before you've earned their trust. If you know they don't want you there, then you have to come in and sit down. Have a chat and be pleasant, maybe have a coffee. Do what they want, not what's in your assignment for the day. Forget the assignment for a while, maybe two, three times. Don't worry if it gets dirty. You can tackle that later, the dirt in the flat.

In everyday work it is easy to forget the "human element”, as some assistant nurses and nurse's assistants say-sitting down with a cup of coffee and exchanging a few words. Cutbacks and restructuring in home help services tend to focus solely on distributing medicines: “The pills aren't the important thing in all this, it's those five minutes when you sit down with them and maybe they put on some coffee and you chat with them. That's what they need, more than pills”, an assistant nurse emphasises.

A social worker points out the necessity of process thinking, which involves taking one step at a time in the encounter with the client. This ensures that the client is involved too, even if the working process initially seems far too slow. However, taking one step at a time also ensures a reasonable workload. Otherwise the tasks can become overwhelming. "You can't keep thinking that you have to do everything - that's too much. I could never get through the day. You have to take it bit by 
bit." What is needed in the context is thus to be aware of processes going on in the relationship between individuals, not just between professional and client. This kind of approach also helps to lighten the professional's own workload (Rönning, 2002). For example, one does not need to be anxious to do everything in a hurry; rather, it is important to affirm and summarise the other's perspective, whether dealing with a family member or an older person in need of assistance and support.

In order to create a relationship in the encounter with the clients, the overall requirement may be simply to allow for quality time to have a chat, adopt a process-thinking and striving to gain the person's trust before even initiating any practical action. Under the next heading, we share with the reader a longer excerpt showing how the discussions in the focus groups evolve in a dialogue between the participants and in relation to the moderator. The excerpt illustrates situations when it is by definition difficult to create reciprocity with the client, as when the older person is suffering from a psychosis and/or a dementia disorder. The encounter is just as much about identifying the older person's mental and emotional state at the moment while not allowing the person to lose face (Goffman, 1959/1990).

\section{White Lies and Modifications of the Truth- Maintaining a Moral Distance}

An assistant nurse, here called Tina, works at a supported housing facility. She is flexible and responds in a delicate way without trying to create order or showing any moralising attitude. If the older person is in her own psychotic world, handing Tina a series of objects that only exist in her own mind, Tina just accepts the imaginary gifts. The following excerpt is quite long, but clearly illustrates how Tina and Nike, another assistant nurse who works in the home health services, reason about the necessary attitude in relation to their clients:

Tina: This lady is hallucinating wildly. She is sitting there just gathering things, like this. [Tina illustrates with hand gestures.] Today I had my pockets packed with things she gave me. I just took them from her and put them in my pocket. Of course there's nothing there. But it calms her down. Everything is OK when I take these [imaginary] things she gives me.

Moderator: But what else can you do?

Tina: Actually those [other colleagues] who don't understand this will probably say that "there is nothing there, your hands are empty". Because of course she doesn't have anything in her hands, but I pretend to receive things and I put them in my pocket.

Nike: Yes, because to her they are real.

Tina: Yes, because to her these things do exist. This morning she had a little child in her bed, and she was searching in her bed when I entered. She got up and started to search. You just have to play along.

I work with people with dementia. This is something I've done a long time-not protesting, because in their world it is actually real. "Going home to Mum or Dad" or wanting to go home or to work. When darkness falls, it all comes up, just like that. There's no point in saying, "Your Mum and Dad aren't alive anymore." That would just cause more harm and trouble, because it causes grief that they have to go through every time, eighteen times a day. /.../

I often say, "I will never get to heaven because I lie all day, every day." /.../ When the lady says: "But I have to go home to Mum and Dad", I say, "Oh no, it's so dark outside and the roads are very slippery, can't you stay here tonight and then go tomorrow?" "Yes, well, perhaps that's a good idea." /.../

You live with the idea that your Mum and Dad are there at home and then I come and say, "But your Mum and Dad are not alive anymore, they've been dead for a long time." It's a huge blow every single time I tell them.

Nike: Yes, especially if you have dementia.

Tina: Well, since they don't remember.

Nike: No. I usually just agree. They may be hallucinating that they have a cat or that they have a baby or that they have some boy coming to dinner or whatever.

Moderator: But what happens if they say that they want to lay the table for this boy coming to eat dinner tonight, what do you do then?

Tina: We just do it.

Nike: We just do it.

Tina: Or I might say, "Oh, he just called and said that he can't come tonight because the roads are so slippery." Sometimes it works, sometimes it doesn't. If it doesn't, then you have to lay the table.

Nike: And sometimes when you come the table is already laid out with nice china and everything.

Tina: But is this really lying? Or is it bending the truth? Or a white lie? Or what can we call it?

Moderator: Yes, because you just said that it is true in their world?

Nike: Yes, in their world it is like that. And sometimes you are not permitted to clear the table. No, no. It's up to the boy, who was visiting and didn't do his part. It's his job to clear the table. So you have to let it be, and then when I come back the next time and she is not in the kitchen, then I clear the table.

Well, there's no point in doing something else because then she just gets cross. She can throw him [the imaginary boy] out too if she pleases. She can be very unkind towards certain staff if you don't know how to handle her.

Tina's and Nike's colleagues sometimes feel compelled to tell their clients the truth, even if it means telling the client that her parents are dead, which may mean that the person receives the terrible news over and over again at brief intervals throughout a whole day. Tina describes how she had to work on her attitude to prevent herself lecturing the client on what is true or not. For Tina and Nike, the older persons are not purely objects of care, but also people with human emotions. Being close to the older clients and understanding their situation affects the relationship. Even if the older person is not always very nice, a professional must not compromise on her approach to the client. Tina and Nike also avoid telling painful or hurtful truths. Both are willing to pretend or lie- “all day, every day”to protect the client's feelings, since lying can be described as a protective action (Goffman, 1959/1990), the lies must be classified as "white lies". In Sweden, as elsewhere in the world, lying is considered wrong and immoral, or as Tina puts it in cultural terms, you “won't get to heaven”. But Tina and Nike do not fall to the temptation to state obvious truths, nor do they try to convince the older client of what is real. Rather, both assistant nurses maintain a moral distance-in particular to their own actions, meaning that it is okay to lie as long as it is out of concern for the client's feelings. The attitude of these assistant nurses can be compared with Day et al.'s interviews with people with dementia disorders, who were not averse to lies as long as the staff personnel were aware of why they were lying, and that it was out of concern for the older client (Day et al., 2011). 


\section{Awareness of the Family Members' Feelings}

A home help services coordinator, Amina, explains that she has developed an approach in which she avoids becoming defensive when family members call to complain about the services. Instead, she tries to structure the discussion by asking "those follow-up questions". She exemplifies this with a short story about putting up with and bearing the family members' emotions and accepting their experiences by listening-without making excuses or belittling the complaints.

One family member was very angry that her mother hadn't had a shower. The trick is to ask, "What do you think happened?" And then listen, because she was really upset. So I listened. I asked those follow-up questions.

We came to an understanding and we concluded the discussion on a positive note.

The coordinator understands the daughter's bitterness, but does not judge it. She simply comments on the existing situation, without getting upset or defensive. She goes out of her way to ask the daughter how she perceives the situation. At the same time the coordinator shows her willingness to listen and ask follow-up questions, as well as to tolerate the daughter's anger without dismissing or belittling it. This is what psychotherapists call holding (Slochower, 1996). The coordinator makes sure that the conversation does not have to result in the daughter staying upset. They can come to an agreement. Not about why the mother didn't have a shower, but simply about the daughter's right to express her feelings and her interpretation of the situation.

It is not a requirement that the professional must always do or perform something at every encounter with a client or a family member, before a reciprocal relationship has been established. Simply being there and listening is a good first step, and in fact a necessity for establishing reciprocity between the professional and the client or family member. It is meaningless to focus solely on getting things done to make the client-or the client's family-happy. Really, the professional does not always know what is best or what should be done, despite their training and many years of experience. Sometimes you need to wait and assess the situation. The best way to do that is by asking "those follow-up questions". The client does not need to take a proactive role either; one occupational therapist explained that it was often the reverse, that it was about "teaching the person to resolve their own problems". What the participants in the focus groups are discussing is the complexity of working with people who have mental health problems, as one nurse points out; You don't just barge in and say, "Off we go, time for a shower!”

\section{Being a Buffer between the Client and Family Members}

When a professional understands that interventions are not all that matters, they may also tolerate serving as a buffer between the clients and their family members who not only have expectations, but also make demands. Puck works as an assistant nurse on a night shift. She talks about a man who sits up all night and his sister regularly calls the home help services to complain; "He has a sister who is hysterical about his sleeping at night."

Puck: He sits up listening to opera and drinking two or three beers. I think he has a pretty nice life. The only thing we usually do there is ask if he'd like a sandwich with his beer. Rather than forcing him into bed.

The sister got really angry at me when I said that we used to ask if he might like to go to bed, but we've stopped asking, because he doesn't want to. If he ever does want to rest, he doesn't tell us. But we do make sure he has what he needs. She probably thought I was bonkers when I said that I think it's an unusually good quality of life to have a beer at night and listen to opera and be served a sandwich.

To me that's quality of life and I'm happy to give it. That's something I stand by. She can report me if she wants, I stand by what I do. I just make sure he is as comfortable as he can be and that he doesn't hurt himself.

I try not to force him to go to bed. If he wants to sit up, then don't come and try to make him go to bed, if he wants to listen to opera and drink beer. Sometimes I can say; "Can you turn down the volume a bit, not everyone likes this kind of music."

Puck's narrative illustrates her approach in the encounter with the sister and the man who "sits up listening to opera and drinking two or three beers". She does avoid an open conflict with the sister, but she clearly takes a side. Puck even points out that she may well is the catalyst, giving the man the opportunity to "drink his beer". She does not moralise about the older man and has no intention of forcing or trying to influence the man or intervene by asking him to go to bed, stop drinking or turn off the music. Puck is clearly the central figure in the story because she tolerates the sister's anger and is aware of the risk of being reported. When Puck asks the man to lower the volume, this is an expression of what Goffman (1959/1990) calls taking a protective attitude towards the older man so that he can continue to find satisfaction in his everyday life. Put differently, Puck can be said to serve as a buffer between the client and his sister who wants him to change his life.

\section{Discussion}

The reasoning in our five focus groups shows how the staff members come to the understanding that their approach and encounters contain dimensions of both talking and doing. Very often, the talking is a necessity before the doing is even possible. On an overall level, the staff members describe their professional attitude in order to arrive at a mutual understanding at the very moment that they encounter the care clients in their homes or talk to their relatives on the telephone. This cannot be done in any other way than by being focused and anticipating responses throughout the encounter. Thus, the participants in the focus groups express the value of interacting and creating mutual relationships. Clients and their family members are unique individuals with specific needs and wishes. This understanding also implies an awareness of the importance of gentleness (Mcann \& Baker, 2001), and that each staff member has an essential role to play as a shield or buffer against the incomprehension of others, such as demanding relatives.

Challenging situations to the professionals in the focus groups are when the older person in community care is in an acute state of anxiety, is being psychotic and/or confused because of dementia. However, a moralizing attitude is hardly helpful, but will rather complicate the possibility of creating a reciprocal relation. Other challenging situations are when relatives are demanding action. The optimal challenge is to put up with the idea that responding to the client should be considered as not doing anything. What at first could be viewed as an ex- 
pression of negligence and of not doing is in fact being conscious about the position of the other person. It is an emotional and professional work, but not in order to fix, since rectification does not have any intrinsic value or a value on its own. The professional have to wait and assess the situation even though relatives and colleagues are expecting the professional to be action oriented. An instrumental attitude, i.e. caring without emotion and awareness about the care receivers emotions is abominable (Rönning, 2002), professionals should instead focus on the process of caring. All this doing must be impregnated by sense of tact (Goffman, 1959/1990).

The home of an old person with mentally health problems could be considered as back stage (Goffman, 1959/1990). When a staff member enters the home it turns into a public place, a front stage, since the staff can, for example, gossip about the older person back stage. If the old person does not feel well the home is even less private, since s/he is unable to control how $\mathrm{s} /$ he is perceived and therefore dependent on the attitudes of the staff maintaining protective measures to avoid embarrassment. A psychotic, confused and demented elderly person may no longer care about the region in which s/he is. The older people's vulnerability and inadequacy asks even higher demands on staff. The question is whether it is for the sake of the elderly. Or for the staff's sake? Perhaps the attitude is related to one's own future role as older? But there is also another interpretation. The staff would not itself be exposed, which in itself is not rational behavior. The staff would actually let the elderly maintain their dignity. Consistently emphasized during the interviews are that the elderly who suffered from mental illness are also "human beings". Even if the elderly do not care themselves the staff members do. Employee behavior brings an ethical dimension to the work. They are equally interested in ethics as a higher allusion. They do not consider the older disadvantageous because their work would then have a different content. It would actually reduce their status. Actually, one could say that their reasoning indicates a status marker, where the staff recognizes the value of, or the status of one's work. Staff members have their own status to argue.

We began this article by reasoning-with a reference to Topor (2005)—-that the de-institutionalisation reasonably ought to create conditions for a more reciprocal interaction between care staff and older people with mental health problems, such as mental illness or disabilities. But institutional thinking isn't just about four walls, a floor and ceiling, nor does it imply that people live in their flats completely separate from the rest of society. Institutional thinking is obviously conveyed in the daily actions, feelings and reflections of professionals. The staff members' approach is crucial here, as is their awareness of their attitudes. The essence of our results seems to be that an old mentally ill or disabled person who becomes a care receiver has the right to keep face and therefore their dignity (Goffman, 1959/1990). Without moralising, or truthfully informing the older client that her parents are long dead, or explaining that there is no boy coming to dinner. And without telling the client to stop drinking beer, shut off the music and go to bed, or chastising the client for wetting his pyjamas or bed. Professionals do not need to be moral police; however, they do need to deal with and reflect on their own morals. Our results show that the interviewed professionals are able to approach these older clients on the clients' own terms. This can be interpreted as maintaining a relationship in the interface between people, in a reciprocity, which requires insight into and understanding of what it means to be a part of the alliance in the everyday encounters between older people with mental health problems (McCann \& Baker, 2001).

However, we also want to emphasise other aspects of understanding our data. The narratives in the focus groups reveal how the participants put their professional attitude to the test, and also how they analyse their feelings and moral attitudes above all in relation to their clients. This is comparable to MacCann and Bakers expression, the process of tuning in. The professionals in our study demonstrated what we would like to call an emotional and moral consciousness, in part by relating to their discomfort and possibly feelings of inadequacy, along with various demands and expectations for their doing, in the company of colleagues. It was not always pleasant to put up with family members who had differing opinions on the need for care or how quickly actions needed to be carried out; it was, however, strength to be open to the wishes of the care users. Based on the reasoning of the focus group participants, one can never be satisfied with the level of reciprocity; it cannot be static, but requires an understanding of the conditions of the alliance. It is also essential to obtain emotional feedback, as highlighted by Rönning (2002)—quite simply to ensure the satisfaction of the caregivers themselves.

Altogether, everyone in the different focus groups highlights the essence of being involved. The participants present narratives about how they view themselves in this sense. So an addendum to Barron's (2009) comment could be the necessity of developing conditions for a "critically reflective care perspective", or in other words, critically scrutinising one's thoughts and actions, and above all one's feelings and empathetic capacity. This reflection requires an emotional and moral sensitivity, an ability to examine one's attitudes and responses, which we have designated emotional and moral consciousness. The caregivers participating in the focus groups are not just doers; they have compassion too. By interpreting data based on Andersson's (2009a, 2009b) and Barron's (2009) thinking we can understand the value of critically reflective care, in which the staff relate to their own and others' expectations and demands in order to provide good care. This means that we not only need to develop new methods, we must also create space for a reflective attitude. This should be a natural understanding based on how we should treat elderly people with mental health problems, i.e. the essence of critically reflective care.

\section{Clinical Implications}

Prerequisites for a reciprocal relation out of our study are in short:

- Make a connection with the client, before even thinking of being action or task oriented.

- Think in several steps - the situation does not have to be arranged at once.

- Sometimes the personnel have to be a buffer against family members who want their ways of arranging things. Remember that the old person actually is the principal constituent.

- Keep moral distance, never try to rear the clients with mental health problems or oppose truths that at the moment are irrelevant.

- Be conscious about shame-relieve and ease instead of confirming the feeling

- Tricks of the trade can be useful, but integrity and emotional 
sensibility is essential in psychiatric community care of older people with mental health problems.

\section{Acknowledgements}

We would like to give a special thanks to Susanne Brandheim and Therese Karlsson, Ph.D. candidates, and other colleagues within social work at Karlstad University, Sweden, for comments on an early draft of this article and also to our peer reviewer for excellent propositions on our article.

\section{REFERENCES}

Alvesson, M., \& Sköldberg, K. (2000). Reflexive methodology: New vistas for qualitative research. London: SAGE.

Andersson, G. (2009a). Housing support-Interplay, reality, and self image. In M. Sundgren, \& A. Topor (Eds.), Psychiatry as social work. Stockholm: Bonniers.

Andersson, G. (2009b). Daily life and housing support: A study about people with mental disability. Stockholm: Stockholms Universitet.

Barker, Ph. J., \& Buchanan-Barker, P. (2011). Mental health nursing and the politics of recovery: A global reflection. Archives of Psychiatric Nursing, 25, 350-358. doi:10.1016/j.apnu.2011.03.009

Barron, K. (2009). Power awareness in care and social work. In E. Gunnarsson, \& M. Szebehely (Eds.), Genus in daily care. Stockholm: Gothia Förlag.

Berggren, U. J., \& Gunnarsson, E. (2010). User-oriented mental health reform in Sweden: featuring "professional friendship". Disability \& Society, 25, 565-577. doi:10.1080/09687599.2010.489303

Borg, M., \& Kristiansen, K. (2004). Recovery-oriented professionals: Helping relationships in mental health services. Journal of Mental Health, 13, 493-505. doi:10.1080/09638230400006809

Davidson, L., O’Connell, M. J., Tondora, J., Lawless, M., \& Evans, A. C. (2005). Recovery in serious mental illness: A new wine or just a new bottle? Professional Psychology: Research and Practice, 36, 480-487. doi:10.1037/0735-7028.36.5.480

Day, A. M., James, I. A., Meyer, T. D., \& Lee, D. R. (2011). Do people with dementia find lies and deception in dementia care acceptable? Aging \& Mental Health, 15, 822-829.

doi:10.1080/13607863.2011.569489

Deegan, G. (2003). Discovering recovery. Psychiatric Rehabilitation Journal, 23, 368-376. doi:10.2975/26.2003.368.376

Goffman, E. (1959/1990). The presentation of self in everyday life. London: Penguin.

Karlsson, L. B., \& Rydwik, E. (2013). Secure encounters-Making sense of one's professional competence: A focus group study on learning processes.

Karlsson, L. B. (2009). “Schizophrenic or occult harassed?” A narrative study of a self-biographic text about auditory and visual hallucinations. Qualitative Social Work, 8, 83-100. doi:10.1177/1473325008100421

Kvale, S., \& Brinkmann, S. (2009). InterViews: Learning the craft of qualitative research interviewing. Los Angeles, CA: Sage Publications.

Link, B., \& Phelan, J. (2001). Conceptualizing stigma. Annual Review of Sociology, 27, 363-386. doi:10.1146/annurev.soc.27.1.363

Markström, U., Sandlund, M., \& Lindqvist, R (2004). Who is responsible for supporting "long-term mentally ill" persons? Reforming mental health practices in Sweden. Canadian Journal of Community Mental Health, 23, 41-63.

McCann, T., \& Baker, H. (2001). Mutual relating: Developing interpersonal relationships in the community. Journal of Advanced Nursing, 34, 530-537. doi:10.1046/j.1365-2648.2001.01782.x

Morgan, D. L. (1997). Focus groups as qualitative research (Qualitative Research Methods Series Volume 16). Thousands Oaks, CA: Sage Publications.

National Board of Health and Welfare (2008). Older peoples' mental health-A detailed progress report on the prevalence, management and initiatives.

http://www.socialstyrelsen.se/Lists/Artikelkatalog/Attachments/8850 /2008-131-20_200813120.pdf

Regeringens proposition 1993/94:218. Psykiskt stördas villkor. http://www.riksdagen.se/sv/Dokument-Lagar/Forslag/Propositioneroch-skrivelser/prop-199394218-Psykiskt-stor_GH03218/

Rydwik, E., Karlsson, L. B., Strandberg, L., \& Mattson, P. (work in progress). Secure meetings-An evaluation of an education project. Stockholm: Stockholm County Council.

Rönning, R. (2002). In defence of care: The importance of care as a positive concept. Quality in Ageing and Older Adults, 3, 34-43.

Slochower, J. A. (1996). Holding and psychoanalysis: A relational perspective. Hillsdale, NJ: Analytic Press. www.socialstyrelsen.se/omsocialstyrelsen/organisation/regeringsupp drag/kompetensforstarkningforperson1-date110613

Thomas, C., \& Rose, J. (2010). The relationship between reciprocity and the emotional and behavioural responses of staff. Journal of Applied Research in Intellectual Disabilities, 23, 167-178. doi:10.1111/j.1468-3148.2009.00524.x

Tierney, K. R., \& Kane, C. F. (2011). Promoting wellness and recovery for persons with serious mental illness: A program evaluation. Archives of Psychiatric Nursing, 25, 77-89. doi:10.1016/j.apnu.2010.07.006

Topor, A. (2005). New and old institutions. In M. Sundgren, \& A. Topor (Eds.), Social psychiatry. Stockholm: Bonniers. 